\title{
Effects of removal of seagrass canopy on assemblages of small, motile invertebrates
}

\author{
Rod M. Connolly* \\ Department of Zoology, University of Adelaide, South Australia 5005, Australia
}

\begin{abstract}
To test the importance of seagrass canopy to epifaunal invertebrates in a southern Australian estuary, patches of the short, fine-leaved seagrass Zostera muelleri Irmisch ex Aschers. were cleared of canopy. All other factors were known to be consistent with seagrass presence, and a procedural control was used to measure any effects of the method used to remove seagrass. Effects on epifauna were measured as changes in abundance and biomass of key taxa and in total production, and as differences amongst assemblages, tested using an analysis of similarity (ANOSIM) randomisation routine. Removal of seagrass canopy had a weak but detectable effect on epifauna over and above the slight effect caused by the disturbance concomitant with seagrass removal. Epifauna associated with habitat from which seagrass had been removed did not, however, match that from areas unvegetated prior to the experiment. The epifauna from these previously unvegetated areas were characterised by low abundance and biomass of several key taxa, apart from 1 group, cumaceans, which were far more common in this habitat The results suggest that the overriding importance of $Z$. muelleri to epifauna is not simply the presence of seagrass canopy, and explanations of the higher atundance of epifaunal invertebrates in vegetated compared to unvegetated habitats based merely on the presence of seagrass canopy are not supported.
\end{abstract}

KEY WORDS: Zostera Macrofauna C Crustacea Predation $\cdot$ ANOSIM

\section{INTRODUCTION}

The abundance of small, motile invertebrates associated with seagrass is usually greater than that associated with adjacent unvegetated patches (Orth et al. 1984). This difference is more obvious for epifauna (animals associated with the leaf and sediment surfaces) than infauna (animals buried within the sediment) (Howard et al. 1989). Abundances of small fish are also greater in seagrass areas than in adjacent unvegetated areas (Beil \& Pollard 1989), and seagrass meadows are thought to provide nursery areas for juveniles of many commercially important species (Pollard 1984). Epifauna, especially crustaceans, are the predominant prey of most small fish associated with seagrass beds, including juveniles of commercially important species (Klumpp et al. 1989)

\footnotetext{
- Present address: Faculty of Environmental Sciences, Griffith University, Nathan, Queensland 4111, Australia
}

Epifaunal assemblages associated with adjacent patches of different species of seagrass are often more similar than those associated with patches of the same species of seagrass separated by large distances (Howard et al. 1989). Artificial seagrass placed in unvegetated areas near natural seagrass beds attracts a fauna similar to that in the natural beds (Howard et al. 1989, Edgar 1990b). Howard et al. (1989) suggest that the type of seagrass may be less important than the presence of seagrass. Larger epifaunal invertebrates (macrofauna, defined as animals retained on $0.5 \mathrm{~mm}$ mesh) are, however, capable of selecting amongst different densities of seagrass (Leber 1985). Bell \& Westoby (1986b) manipulated seagrass densities in field experiments and used predator exclusion cages to show that decapods were more common in denser seagrass regardless of the presence or absence of predators. They showed convincingly that low decapod numbers in patches with less dense seagrass cover were not due to increased predation, and concluded that decapods select habitat. Stoner (1980) demon- 
strated that amphipods can also detect and respond to differences in canopy density. The high mobility of epifaunal invertebrates, even in their adult stages, enhances their ability to exercise behavioural selection for seagrass of differing densities. Although less experimental work has been done on smaller epifaunal invertebrates (Howard et al. 1989) (meiofauna, defined as animals passing through $0.5 \mathrm{~mm}$ mesh but retained on $0.1 \mathrm{~mm}$ mesh), harpacticoid copepods are known to colonise artificial seagrass placed near natural seagrass beds (Bell \& Hicks 1991).

The Barker Inlet - Port River region of South Australia is a shallow, marine-dominated estuary comprising extensive intertidal areas with either eelgrass (Zostera muelleri Irmisch ex Aschers., Heterozostera tasmanica Martens ex Aschers.) cover or no vegetation. Abundances of small fish are much greater in eelgrass patches than over unvergetated patches (Connolly 1994a), as are abundances of epifauna (Connolly 1994b). Both meio- and macro-epifauna, especially crustaceans and polychaetes, are a major component in the diet of most fish species caught in the estuary (Connolly 1994b). In the present study, therefore, the aim was to sample epifauna of all sizes. The health of eelgrass in the Barker Inlet - Port River region is threatened by many of the human activities causing seagrass decline in other sheltered coastal areas (such as nutrient input, changed drainage regimes, and land reclamation for urban development (Walker \& McComb 1992). North of the estuary, adjacent to Adelaide's main sewage outfall, a strip of intertidal eelgrass almost equal in area to the entire area of eelgrass within the estuary has been lost (Shepherd et al. 1989).

Attempts to demonstrate the importance of seagrass have mostly involved the construction of patches of artificial seagrass in unvegetated areas. An alternative is to remove seagrass from areas where it is naturally occurring. This bears more directly on the question: what is the effect of seagrass loss on fauna? The disadvantages of seagrass removal are firstly that regrowth necessitates either a short-term experiment or repeated removal, and secondly that seagrass removal is irresponsible except when working with species that recover quickly.

The aim of the present study was to determine the effects on epifaunal abundance and community composition of removing above-ground vegetation (seagrass canopy). If the seagrass canopy is important, then patches from which the vegetation has been removed should support fewer invertebrates and different invertebrate assemblages than seagrass patches. Furthermore, if the presence of the seagrass canopy is the important difference between seagrass and unvegetated habitat, then invertebrate assemblages associated with patches from which the seagrass canopy has been removed should match assemblages from patches which were unvegetated prior to the experiment.

\section{MATERIALS AND METHODS}

The experiment was done in South Australia in the Barker Inlet - Port River region $\left(34^{\circ} 45^{\prime} \mathrm{S}, 138^{\circ} 30^{\prime} \mathrm{E}\right)$ in conjunction with an experiment into the role of seagrass as fish habitat (Connolly 1994c). The estuary is strongly tidal, typically with 2 tides $\mathrm{d}^{-1}$, and with a maximum tidal amplitude of $2 \mathrm{~m}$. The experiment was sited low in the littoral zone, with all plots at a similar level. The area is dominated by Zostera muelleri, a fast growing, colonising species.

The small, motile invertebrates associated with the eelgrass canopy and sediment surface (epifauna) worc collected from the following 4 habitats (treatments) marked as $5.5 \times 5.5 \mathrm{~m}$ squares: (1) eelgrass in natural state (control $=\mathrm{C}$ ); (2) eelgrass removed by cutting with shears at the sediment surface whilst emergent on low tides (removed $=\mathrm{R}$ ); (3) eelgrass uncut, but with equivalent time and effort spent at the site mimicking cutting (procedural control $=$ P); and (4) unvegetated mudflat (unvegetated $=\mathrm{U}$ ).

Six eelgrass patches were assigned to each of the first 3 treatments in a randomised block design. That is, 1 replicate of each of the first 3 treatments was assigned at random to 6 randomly selected areas (blocks) along a $1 \mathrm{~km}$ stretch of shore. The unvegetated treatment could not be randomly assigned. Instead, the nearest unvegetated patch to the block occurring at the same height in the intertidal was selected as the unvegetated patch. The blocked design guaranteed interspersion.

Patches were sampled $13 \mathrm{~d}$ after the preparation of treatments. This was a short enough interval to avoid eelgrass regrowth. Epifauna were collected from 3 randomly placed sites within each patch, subject to the restriction that a $0.5 \mathrm{~m}$ wide strip around the perimeter of the patch be avoided. Collections were made on the daytime rising tide in water depths between 30 and $50 \mathrm{~cm}$. A $95 \mu \mathrm{m}$ mesh net with a $25 \times 25 \mathrm{~cm}$ opening was used, following the method of Sergeev et al. (1988) in which the net was placed rapidly over the canopy onto the sediment. Whilst the net was held in place, shears were slipped under the net and seagrass, where present, was cut level with the sediment surface. In habitats without seagrass, the same action was taken, ensuring that the sediment surface was ruffled as it was where seagrass was present. The net was then slipped off its frame and dragged shut along the sediment surface. Animals were later separated into sieve size classes of $2 \mathrm{~mm}, 1 \mathrm{~mm}, 500 \mu \mathrm{m}, 250 \mu \mathrm{m}, 125 \mu \mathrm{m}$ 
and $75 \mu \mathrm{m}$ before being identified to major taxa and counted. Numbers of very abundant taxa were counted from random subsamples with the aim of counting between 50 and 200 individuals of each taxon per sieve size in any sample. Taxa are listed in Table 1 Motile epifauna is the predominant food of nearly all fish associated with shallow seagrass beds (Klumpp et al. 1989), and total epifaunal abundances from this experiment have also been used in an attempt to explain effects of canopy removal on small fish (Connolly 1994c). Nematodes are typically not a component of fish diets [but see Gee (1989) for exceptions], and were therefore treated separately in analyses. Nematode numbers are presented in this paper but have been excluded from estimates of total epifaunal abundance and from multivariate analyses except where stated Ash-free dry weights (AFDW) were calculated by converting abundances for each taxon for each sieve size using Edgar's (1990a) equation, $\log B=a+b \log S$ where $B=$ AFDW $(\mathrm{mg}), S=$ sieve size $(\mathrm{mm})$ and $a$ and $b$ vary depending on broad taxonomic category. This permits estimation of epifaunal production using Edgar's (1990a) equation, $P=0.0049 B^{0.80} T^{0.89}$, relating production $\left(P, \mu \mathrm{g} \mathrm{d}^{-1}\right)$ to sample $\operatorname{AFDW}(B, \mu g)$ and water temperature $\left(T,{ }^{\circ} \mathrm{C}\right)$. The mean water temperature over all collecting days of $16.0^{\circ} \mathrm{C}$ was used.

The surface area of eelgrass leaves within all patches that supported eelgrass prior to the experiment was estimated before setting up the experiment and again after sampling of epifauna. Leaf area was calculated for each patch from measurements of the number of leaves per $400 \mathrm{~cm}^{2}$ quadrat, and the length and width of 10 leaves, at 5 randomly selected sites. Prior to the experiment, leaf area did not differ between patches selected for the 3 treatments involving eelgrass $(\mathrm{C}$ : $1.54 \mathrm{~m}^{2}$ leaf area $\mathrm{m}^{-2}$ sediment surface; P: 1.31 ; $: 1.39$; ANOVA, $p=0.651$ ). After removal, the leaf area within patches of treatment $R$ was reduced almost to zero, whilst patches of $\mathrm{P}$ remained similar to patches of $\mathrm{C}$ (C: 1.55 ; P: 1.46; R: 0.02; ANOVA, p < 0.001; Tukey HSD pairwise comparisons, $\mathrm{CP}$ R).

\section{Data analysis}

Epifaunal assemblages [described both by abundance and biomass (AFDW)] from the 4 habitats were compared using an analysis of similarities (ANOSIM), which is a non-parametric analogue to a multivariate analysis of variance (MANOVA) without the assumption of multivariate normality. ANOSIM has an addi-
Table 1. List of taxa into which animals were grouped

$\begin{array}{ll}\text { Crustacea } & \text { Non-crustacea } \\ \text { Caridea } & \text { Pol } \\ \text { Mysidacea } & \text { Polychaeta } \\ \text { Amphipoda - Gammaroidea } & \text { Bivalvia } \\ \text { Amphipoda - Caprellidea } & \text { Ophiuroidea } \\ \text { Tanaidacea } & \text { Actiniaria (Anemones) } \\ \text { Isopoda } & \text { Ascidiacea larvae } \\ \text { Cumacea } & \text { Nematoda } \\ \text { Copepoda - Harpacticoida } & \\ \text { Copepoda - Cyclopoida } & \\ \text { Copepoda - Calanoida } & \\ \text { Copepoda - nauplii (unidentified) } & \\ \text { Ostracoda } & \end{array}$

tional advantage over MANOVA in being able to detect differences between groups without the assumption of similar variance within each group (Clarke 1993). ANOSIM compares ranked similarities between and within groups selected a priori using a randomisation test for significance. A 2-way ANOSIM without replication (randomised block ANOSIM) was used to test for habitat and block effects, using averages of the 3 samples from each patch. This analysis makes a sensitive test for habitat effects, but cannot be used to find differences between pairs of habitats once a significant global habitat effect has been shown (Clarke \& Warwick 1994). A nested ANOSIM was also done, ignoring blocks, and treating patches as a nested factor (patch) within the main factor (habitat). This nested ANOSIM tested whether assemblages differed amongst the 4 habitats by treating the 3 samples from each patch as a single collective estimate of the fauna from the patch. After a significant difference was detected using this global ANOSIM test, the same technique was employed to test pairwise differences between habitats. All ANOSIM tests involved 5000 simulations using the PRIMER package from Plymouth Marine Laboratory, U.K

The relationships amongst assemblages from each patch are graphically represented using non-metric multidimensional scaling (MDS), an ordination technique that uses the same matrix of ranked similarities as ANOSIM. MDS displays samples in low (usually 2) dimensional space while retaining as nearly as possible the similarity rankings between samples. The ordinations presented were done on data averaged over the 3 samples within each patch to simplify presentation and make habitat groupings clearer. Ordinations were also done using all 72 individual samples, and habitat groupings were very similar to groupings using averaged data.

For comparisons of epifaunal assemblages, raw counts were transformed using $x^{0.25}$ to emphasise the 
distribution of less common taxa in the analysis. The Bray-Curtis similarity coefficient was used throughout, as a meaningful and robust measure (Clarke 1993).

Analysis of the similarity matrix used in MDS and ANOSIM has also been used to highlight taxa making a large contribution to between-group differences (Clarke 1993).

The association between epifaunal assemblages and a linear sequence of sites (here the position of a patch along the shore) can be measured using the Index of Multivariate Seriation, and can be tested for statistical significance using a randomisation routine (Clarke et al. 1993). The position of a patch was described as the distance from the first patch at one end of the experiment. For this analysis the data from each sample within a patch were averaged to give just 1 assemblage per patch.

The abundance and biomass of epifauna (all taxa combined and key taxa separately) and total epifaunal and crustacean production from the 4 habitats were compared using analysis of variance (ANOVA). With 3 samples from each patch, the design could be considered as a 2-way (randomised block) ANOVA with no replication, with multiple values within a patch nested within the (figurative) interaction term. Adding a nested factor to a randomised block ANOVA, which in
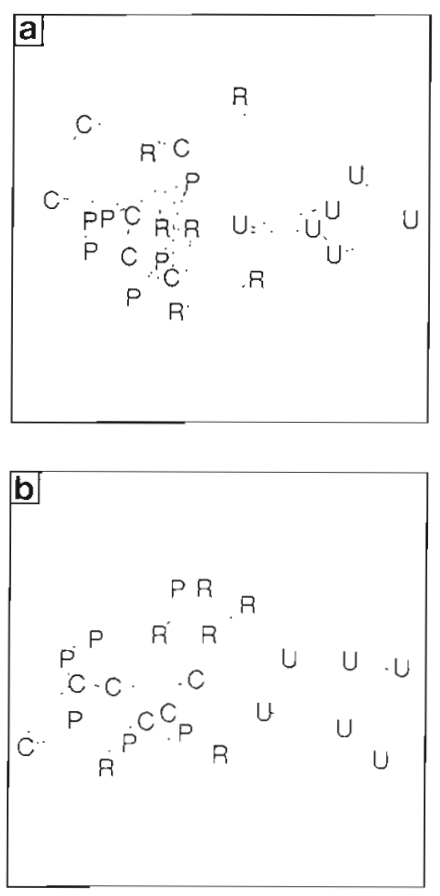

Fig. 1 Two-dimensional MDS ordination plot of epifaunal assemblages, averaged for the 3 samples within each patch, based on (a) abundances (stress $=0.143$ ) and (b) biomasses (stress $=0.150$ ). C: control, $\mathrm{P}$ : procedural control, R: eelgrass removed; U: unvegetated itself requires some risky assumptions, would make a very tenuous test given the small number of samples at all levels. I avoided this by testing data in 2 ways, matching the multivariate analyses described above. First, the 3 measures within a patch were averaged and data were tested using a randomised block ANOVA. Since the primary aim of allocating treatments to blocks was to guarantee interspersion rather than to search for differences along the coast, I then tested by ignoring blocks and treating patches as a nested factor (patch) within the main factor (habitat). Where habitat differences were significant, Tukey HSD pairwise comparisons of habitat means used variance estimates from replicate patches, not from samples nested within patches. Sample variances increased with increasing means, and all univariate analyses were performed on $\log _{10} x$-transformed data for $\log _{10}(x+1)$ where zeros occurred] after checking that the transformation increased homoscedasticity. Significance levels are 0.05 throughout the paper, except where stated otherwise. No adjustment has been made for testing each taxon separately (see Tables $3 \& 4$ ); results for each taxon should be seen as pieces of evidence from 1 experiment.

\section{RESULTS}

Two-dimensional ordination plots showed a very similar pattern on both abundances (Fig. 1a) and biomasses (Fig. 1b). Assemblages from patches of habitat $U$ were grouped separately from those of other habitats. Differences amongst the other 3 habitats were less obvious. Assemblages from habitats $C$ and $P$ overlapped considerably, and those from habitat $\mathrm{R}$, whilst overlapping with $\mathrm{C}$ and $\mathrm{P}$, tended to group more distinctly and be positioned closer to habitat U. The 2-way ANOSIM without replication showed a strong effect of habitat and not of block on both abundance and biomass (Abundance: Habitat, $\mathrm{p}=0.008$, Block, $\mathrm{p}=0.55$; Biomass: Habitat, $p<0.001$, Block, $p=0.95$ ). The nested ANOSIM test for differences amongst habitats detected significant differences using both abundance and biomass data (Table 2). On abundance data, assemblages from habitat $U$ were different from those of all other habitats, and no differences were detected amongst habitats $C_{1} P$ and $\mathrm{R}$. On biomass data, assemblages from habitat $\mathrm{U}$ were different from all other habitats, habitats $C$ and $P$ were not separate, and habitat $\mathrm{R}$ was different from $\mathrm{C}$ but not from P (Table 2). The ANOSIM results confirm the patterns evident in ordination plots, except that habitat $\mathrm{R}$ was found to be intermediate between habitat $\mathrm{U}$ and habitats $\mathrm{C}$ and $\mathrm{P}$ on biomass data only. Assemblages differed amongst patches within habitats using both abundance and biomass data. 
The correlation between similarities in epifaunal assemblages and in positions of patches along the shore was not significant based on either abundance $\left(\rho_{\mathrm{v}}=0.098, \mathrm{p}=0.104\right)$ or biomass $\left(\rho_{\mathrm{w}}=0.076, \mathrm{p}=0.113\right)$. A simple overlay of the position along shore of each patch onto the ordination plot of epifaunal assemblages (Fig. 2a, b) shows no obvious pattern and supports the view that epifauna did not change systematically along the shore.

When nematodes were included in the analysis, habitat groups on ordination plots were not noticeably altered. The results of ANOSIM pairwise comparisons using biomass data showed the same differences described above for biomasses, and using abundance data the pattern of differences upon inclusion of nematodes became the same as that for biomass data. On both abundance and biomass data, nematodes were the major contributor to differences between several pairs of habitats. The order of importance of other taxa important in differentiating habitats was unchanged upon the inclusion of nematodes in the analysis. Cumaceans remained the most important taxon distinguishing habitat $U$ from the other habitats.

Mean abundances in each habitat of total epifauna and of key taxa contributing to differences amongst assemblages are shown in Table 3, along with ANOVA and Tukey results. Using a randomised block ANOVA, no significant block effect was detected for any taxon except cumaceans, and even for this taxon, habitat differences were significant after accounting for effects of block. In all cases where

Table 2. Results of ANOSIM comparisons amongst epifaunal assemblages Results are probabilities. Pairwise tests are for differences between pairs of habitats: C: control; P: procedural control; R: removed; U: unvegetated. Significance level for each pairwise comparison is 0.0083 so that overall significance level for 6 comparisons is 0.05 (ns: not significant). Contributing taxa are those making a consistently large contribution to differences between samples from the 2 habitats, listed in order of decreasing importance. See Table 1 for list of taxa abbreviations

\begin{tabular}{|c|c|c|c|}
\hline Variable & $\begin{array}{l}\text { Global } \\
\text { ANOSIM result }\end{array}$ & $\begin{array}{l}\text { Pairwise } \\
\text { ANOSIM results }\end{array}$ & $\begin{array}{l}\text { Main contributing } \\
\text { taxa }\end{array}$ \\
\hline Abundance & $\begin{array}{l}\text { Habitat }<0.001 \\
\text { Patch }<0.001\end{array}$ & $\begin{array}{ll}C, P & 0.593 \mathrm{~ns} \\
C, R & 0.017 \mathrm{~ns} \\
C, U & 0.002 \\
P, R & 0.128 \mathrm{~ns} \\
\mathrm{P}, U & 0.002 \\
R, U & 0.002\end{array}$ & $\begin{array}{l}\text { Amp, Cal, Pol } \\
\text { Tan, Gas, Har } \\
\text { Cum, Pol } \\
\text { Ost, Gas, Har } \\
\text { Cum, Har, Pol } \\
\text { Cum, Har, Cal }\end{array}$ \\
\hline Biomass & $\begin{array}{l}\text { Habitat }<0.001 \\
\text { Patch }<0.001\end{array}$ & $\begin{array}{ll}C, P & 0.517 \mathrm{~ns} \\
C, R & 0.006 \\
C, U & 0.002 \\
P, R & 0.056 \mathrm{~ns} \\
P, U & 0.002 \\
R, U & 0.002\end{array}$ & $\begin{array}{l}\text { Pol, Gas, Amp, Tan } \\
\text { Gas, Har, Tan } \\
\text { Har, Pol, Cum } \\
\text { Gas, Cal, Har } \\
\text { Cum, Har } \\
\text { Cum, Har }\end{array}$ \\
\hline
\end{tabular}
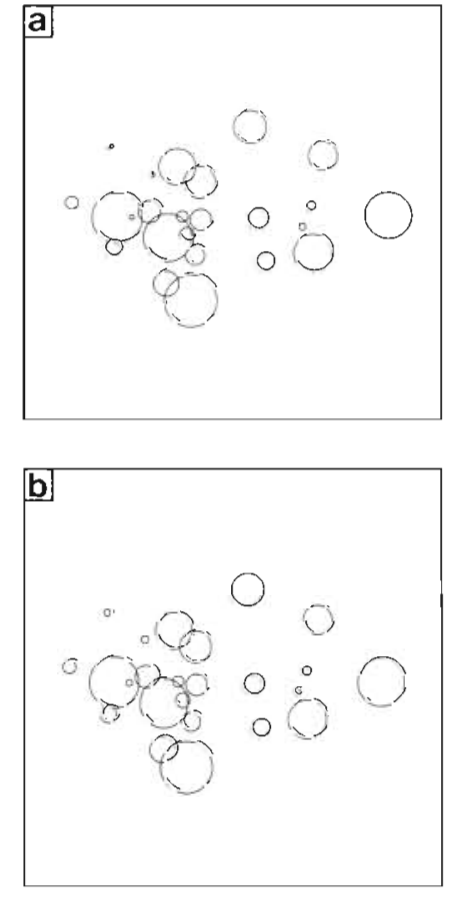

Fig. 2. Overlay of position of patch along shore onto MDS ordination plots in Fig. 1 (a) abundance data; (b) biomass data. Diameter of circle is proportional to distance along shore. Smallest circle $=0 \mathrm{~m}$, largest $=900 \mathrm{~m}$

habitat differences were shown to be significant using the randomised block ANOVA, the nested ANOVA also showed a significant habitat effect. Abundances of all taxa combined and several individual taxa differed between patches within habitats; the habitat differences described above, however, were evident over and above differences amongst patches. The overwhelming trend on abundances was for $\mathrm{C}$ and $\mathrm{P}$ to be similar and significantly higher than $\mathrm{U}$, and for $\mathrm{R}$ to be intermediate between these groups. For some taxa $R$ was significantly different from $\mathrm{C}$ and $\mathrm{P}$ and for others it was not. The exception to this pattern was the group Cumacea, which was significantly more abundant in unvegetated than in the other 3 habitats. Nematodes were more numerous than all other animals combined, and abundances showed the same trend evident in total epifaunal abundances.

Mean biomasses in each habitat of total epifauna and of key taxa contributing to differences amongst assemblages are shown in Table 4. No significant block effect was detected for any taxon 
Table 3. Abundances of total epifauna and key taxa in each habitat. Numbers are means (ind. net ${ }^{-1}$ ). ANOVA results are probabilities; $\mathrm{ns}=$ not significant. Tukey results are for comparisons between pairs of habitats (following nested ANOVA) and show significant difterences as letters not grouped by underlining. C: control; P: procedural control; R: removed; U: unvegetated.

Estimates of variability around means are not shown, as differences amongst means have all been tested for significance

\begin{tabular}{|c|c|c|c|c|c|c|c|c|c|}
\hline \multirow[t]{2}{*}{ Taxon } & \multicolumn{4}{|c|}{ Habitat type } & \multicolumn{2}{|c|}{ Randomised block ANOVA } & \multicolumn{3}{|c|}{ Nested ANOVA } \\
\hline & C & $\mathrm{P}$ & $\mathrm{R}$ & $\mathrm{U}$ & Habitat & Block & Habitat & Patch & Tukey results \\
\hline All taxa combined & 903 & 794 & 381 & 148 & $<0.001$ & $0.759 \mathrm{~ns}$ & $<0.001$ & 0.016 & CPRU \\
\hline Amphipods & 16 & 10 & 6 & 2 & $<0.001$ & $0.507 \mathrm{~ns}$ & $<0.001$ & 0.019 & $\overline{C P R U}$ \\
\hline Tanaids & 3 & 3 & 2 & 0 & 0.011 & $0.192 \mathrm{~ns}$ & 0.017 & $0.082 \mathrm{~ns}$ & $C P R U$ \\
\hline Cumaceans & 1 & 1 & 0 & 12 & $<0.001$ & 0.050 & $<0.001$ & $0.198 \mathrm{~ns}$ & $\mathrm{UCPR}$ \\
\hline Harpacticoids & 590 & 613 & 282 & 105 & $<0.001$ & $0.600 \mathrm{~ns}$ & $<0.001$ & 0.001 & $P \subset R U$ \\
\hline Calanoids & 5 & 11 & 6 & 2 & $0.298 \mathrm{~ns}$ & $0.602 \mathrm{~ns}$ & $0.3 \mathrm{~ns}$ & $<0.001$ & \\
\hline Ostracods & 142 & 32 & 29 & 3 & $0.173 \mathrm{~ns}$ & $0.085 \mathrm{~ns}$ & $0.17 \mathrm{~ns}$ & 0.001 & \\
\hline Polychaetes & 118 & 102 & 43 & 22 & 0.001 & $0.101 \mathrm{~ns}$ & $<0.001$ & 0.003 & CPRU \\
\hline Gastropods & 15 & 9 & 8 & 1 & 0.009 & $0.106 \mathrm{~ns}$ & 0.03 & 0.001 & C PRU \\
\hline Nematodes & 1446 & 1487 & 350 & 97 & $<0.001$ & $0.683 \mathrm{~ns}$ & $<0.001$ & $0.063 \mathrm{~ns}$ & CPRU \\
\hline
\end{tabular}

except ostracods. As for abundances, in all cases where habitat differences were shown to be significant using the randomised block ANOVA, the nested ANOVA also showed a significant habitat effect. Totai epifaunal bromass was not found to differ amongst patches within habitats, but differences were detected for several individual taxa. The general pattern evident in abundance data of similarity between habitats $C$ and $P$, with $R$ intermediate and $U$ lowest, is also present in biomass data, but the trend is weaker. The main difference between abundance and biomass data is that the gap between habitat $U$ and the other habitats is less obvious in biomass data. The narrowing of this gap suggests that the mean biomass of individuals was greater in habitat $U$ than in other habitats. The mean biomass of individuals in each sample was calculated by dividing the total biomass of a sample by the total number of individuals in the sample. The mean biomass of individu- als was highest in habitat $U$ [C: mean $=18.1 \mu \mathrm{g}$ $(\mathrm{SE}=3.6)_{i} \mathrm{P}: 14.2(2.2)_{i} \mathrm{R}: 15.3$ (4.8); U: 24.2 (4.8)], although differences amongst habitats were not significant when tested using a nested ANOVA (Habitat: $\mathrm{p}=0.4 \mathrm{~ns}$ ). Nor did individual biomasses differ significantly amongst patches within habitats (Patch: $\mathrm{p}=0.17 \mathrm{~ns}$ ).

Total epifaunal production and crustacean production in each habitat and results of ANOVA tests are shown in Table 5. Randomised block tests showed that total production and crustacean production varied significantly with habitat but not with block. For both total and crustacean production, production in habitat $C$ was higher than in $R$ and $U$ but was not significantly different from $P . P$ was higher than $U$ and intermediate between, but not significantly different from, $C$ and $R$. $R$ was intermediate between, but not significantly different from, $P$ and $\mathrm{U}$.

Table 4. Biomasses of total epifauna and key taxa in each habitat. Numbers are means (mg). ANOVA results are probabilities; ns: not significant. Tukey results are for comparisons between pairs of habitats (following nested ANOVA) and show significant differences as letters not grouped by underlining: lettering as for Table 3. Estimates of variability around means are not shown, as differences amongst means have all been tested for significance

\begin{tabular}{|c|c|c|c|c|c|c|c|c|c|}
\hline \multirow[t]{2}{*}{ Taxon } & \multicolumn{4}{|c|}{ Habitat type } & \multicolumn{2}{|c|}{ Randomised block ANOVA } & \multicolumn{3}{|c|}{ Nested ANOVA } \\
\hline & C & $\mathrm{P}$ & $\mathrm{R}$ & U & Habitat & Block & Habitat & Patch & Tukey results \\
\hline All taxa combined & 17.8 & 10.8 & 8.9 & 3.8 & 0.039 & $0.669 \mathrm{~ns}$ & $<0.001$ & $0.112 \mathrm{~ns}$ & CPRU \\
\hline Amphipods & 2.4 & 1.1 & 0.5 & 0.3 & 0.030 & $0.111 \mathrm{~ns}$ & $<0.018$ & 0.012 & CPRU \\
\hline Tanaids & 0.4 & 0.3 & 0.4 & 0.0 & $0.229 \mathrm{~ns}$ & $0.497 \mathrm{~ns}$ & $0.04 \mathrm{~ns}$ & $<0.001$ & \\
\hline Cumaceans & 0.0 & 0.0 & 0.0 & 1.7 & $<0.001$ & $0.081 \mathrm{~ns}$ & $<0.001$ & $0.123 \mathrm{~ns}$ & USPR \\
\hline Harpacticolds & 2.6 & 2.8 & 1.1 & 0.5 & 0.001 & $0.946 \mathrm{~ns}$ & $<0.001$ & 0.001 & $P C R U$ \\
\hline Calanoids & 0.1 & 0.1 & 0.0 & 00 & $0.152 \mathrm{~ns}$ & $0.290 \mathrm{~ns}$ & 0.18 ns & 0.001 & \\
\hline Ostracods & 0.5 & 1.1 & 2.9 & 0.0 & $0.380 \mathrm{~ns}$ & 0.023 & $0.7 \mathrm{~ns}$ & $0.5 \mathrm{~ns}$ & \\
\hline Polychaetes & 4.1 & 2.0 & 1.2 & 0.3 & $<0.001$ & $0.899 \mathrm{~ns}$ & $<0.001$ & 0.039 & CPRU \\
\hline Gastropods & 5.3 & 1.0 & 2.4 & 0.5 & $0.340 \mathrm{~ns}$ & $0.802 \mathrm{~ns}$ & $0.26 \mathrm{~ns}$ & $0.363 \mathrm{~ns}$ & \\
\hline Nematodes & 9.7 & 8.6 & 6.9 & 1.7 & 0.003 & $0.420 \mathrm{~ns}$ & $<0.001$ & $0.108 \mathrm{~ns}$ & CPRU \\
\hline
\end{tabular}


Table 5. Total epifaunal and crustacean production in each habitat. Numbers are means ( $\mu \mathrm{g} \mathrm{d}^{-1}$ per $0.0625 \mathrm{~m}^{2}$ ). ANOVA results are probabilities; ns: not significant. Tukey results are for comparisons between pairs of habitats (following nested ANOVA) and show significant differences as letters not grouped by underlining. C: control; P: procedural control; R: removed; U: unvegetated.

Estimates of variability around means are not shown, as differences amongst means have all been tested for significance

\begin{tabular}{|c|c|c|c|c|c|c|c|c|c|}
\hline \multirow[t]{2}{*}{ Taxon } & \multicolumn{4}{|c|}{ Habitat type } & \multicolumn{2}{|c|}{ Randomised block ANOVA } & \multicolumn{3}{|c|}{ Nested ANOVA } \\
\hline & $\mathrm{C}$ & $\mathrm{P}$ & $\mathrm{R}$ & U & Habitat & Block & Habitat & Patch & Tukey results \\
\hline All taxa combined & 170 & 126 & 86 & 50 & 0.014 & $0.646 \mathrm{~ns}$ & $<0.001$ & 0.101 & CPRU \\
\hline Crustacea & 84 & 77 & 51 & 37 & 0.032 & $0.286 \mathrm{~ns}$ & 0.007 & 0.024 & CPRU \\
\hline
\end{tabular}

\section{DISCUSSION}

Expectations based on published surveys showing higher epifaunal abundance, biomass and production associated with seagrass patches compared to adjacent unvegetated patches (Orth et al. 1984) were fulfilled in the present study by the marked differences found between undisturbed (control) eelgrass plots and plots unvegetated prior to the experiment (unvegetated). Removal of eelgrass had a detectable effect on epifauna over and above any effects of disturbance associated with eelgrass removal. The overall effect of removing the canopy was to alter the fauna in the direction of that from unvegetated patches. Removal of canopy did not, however, cause the fauna to match that from previously unvegetated habitat. Assemblages from unvegetated habitat were clearly different from all other habitats, and abundances and biomasses of most of the key species were obviously lower than in other habitats. Cumaceans, which were abundant in habitat unvegetated prior to the experiment, were rare or absent in other habitats.

The results show that the eelgrass canopy does have some importance to epifauna, but that the eelgrass canopy itself is not the only difference, and is not the overriding difference, between patches with and without eelgrass.

The 2 most commonly invoked explanations for the greater abundance of epifauna associated with vegetated habitats are that seagrass provides protection from predation or a greater abundance of food. The role of seagrass in providing protection from predators has received most attention in recent times (Heck \& Orth 1980, see also review by Bell \& Pollard 1989). The work of Bell \& Westoby (1986b) demonstrated that, for the macrofauna they studied, lower abundance in less dense eelgrass was not due simply to predators eating the target species. Macrofauna were rarer in less dense eelgrass regardless of the presence or absence of predators. Bell \& Westoby (1986b) suggested that macrofauna select denser eelgrass (and pointed out that predation may have been the ultimate selective agent for this behaviour). The same habitat selection behaviour can be used to explain the greater abun- dance of epifauna in general in vegetated compared to unvegetated habitats. Epifauna may preferentially select vegetated habitat. It has been shown that macrofauna (Bell \& Westoby 1986b, Virnstein \& Curran 1986, and review in Howard et al. 1989) and meiofauna (Bell \& Hicks 1991) move around over the temporal (2 wk) and spatial (tens of metres) scales used in the present study. The tidal water flow in the Barker Inlet - Port River region increases the chance that invertebrates moved about during the experiment, and that their abundances reflected preferences. The results of the present experiment therefore do not support the model of animals selecting vegetated over unvegetated habitats based on the presence of canopy. The possibility exists, however, that differences between habitats $R$ and $U$ after 2 wk may have been due to species with slow emigration rates lingering on in habitat $R$ even if conditions were unfavourable for long-term survival.

Bell \& Westoby (1986a) point out alternative explanations for the greater abundance of macrofauna in denser seagrass, for example that macrofauna may be attracted to higher abundances of food. The possibility that epifauna are more abundant in vegetated than in unvegetated habitats because they are attracted to higher food abundance has not been tested in the present study. Although removal of eelgrass may have lessened the amount of food available to epifauna (food includes any or all of the following: detritus, bacteria, microscopic algae, and perhaps some of the smaller invertebrates themselves), food availability was not measured.

Other explanations for the greater abundance of epifauna in vegetated habitats are (as listed by Lewis 1984): (1) the presence of physical structure usable as living space; (2) dampened hydrodynamic forces; (3) increased number of microhabitats; and (4) greater stabilisation and deposition of sediment. Results of the present experiment exclude (1) and (2) as plausible possibilities as these explanations are reliant on the immediate presence of above-ground vegetation. The number of microhabitats available to epifauna would have been greatly reduced by the removal of seagrass canopy. All the different heights in the canopy, and positions among shoots, are removed along with the 
canopy. There may be some difference in the number of microhabitats, however, between patches from which seagrass was removed and unvegetated patches, because of the presence of the root/rhizome mat in the former habitat. For this reason, the failure of the fauna in these 2 habitats to match does not necessarily exclude explanation (3) above. Removal of seagrass canopy should render sediment deposition similar to that experienced in unvegetated patches. However, the stability of sediments is very likely to be affected by the retention of the seagrass root/rhizome mat in patches from which canopy was removed, and in any case it may take time after the removal of canopy before sediment becomes similar to that of unvegetated areas. Results therefore do not exclude the possibility that differences in the epifauna from vegetated and unvegetated habitats are caused by differences in sediment characteristics. Another explanation, one not previously considered in the literature, is that epifauna are more abundant in vegetated habitats simply because the canopy causes them to swim more slowly there. Results of the present experiment discount this expianation.

An alternative explanation for the results of this experiment is that, since patches unvegetated prior to the experiment did not receive the disturbance inflicted on patches from which eelgrass was removed, the difference in degree of disturbance may have caused the failure of the fauna of the 2 habitats to match. Another treatment in which unvegetated patches received the disturbance of simulated eelgrass removal could have been used. The same disturbance in eelgrass habitat had only a weak effect on epifauna, and this generates some confidence that disturbance was not important when comparing the 2 habitats without eelgrass canopy; the possibility that degree of disturbance was the important difference between these 2 habitats has not, however, been altogether removed

The differences amongst the epifauna from the 4 habitats lay in the abundance or biomass of taxa, not in the presence or absence of taxa (except for cumaceans). This result may reflect the gross clumping of species and possibly functional groups into single, higher taxa, so that changes in the fauna at these levels would not have been detected. In pollution studies, multivariate analyses at family level reproduce very closely the results obtained at species level, and even analyses at the level of phylum generally agree surprisingly well with those at lower taxonomic levels (Warwick 1988). Warwick has suggested that whole groups (family or higher) may differ in their degree of sensitivity to pollution. In ecological experiments such as the one presented here, however, responses of epifauna at lower taxonomic levels may be of interest.
Depending on feeding preferences of fish, these lower level effects could also be important in determining the suitability of epifauna as fish food. Although the significant differences detected amongst epifaunal assemblages from different habitats demonstrate that the taxa used in this study were adequate for examination of the general question posed about the effects of canopy removal on epifauna, more detailed taxonomic work is needed to make strong assertions about the availability of prey items to particular fish species.

Results from the present experiment apply only to daytime distributions of epifauna. In another experiment examining the effects on epifauna of manipulating seagrass canopy height ( $R$. M. Connolly \& A. J. Butler unpubl. data), epifauna were collected during both the night and day. Abundances and biomasses of key taxa and of all taxa combined were higher at night than during the day, and this is typical of seagrass systems (e.g. Howard 1987). The effects of manipulating canopy height, however, were similar at both night and day.

Epifaunal assemblages, and abundances and biomasses of some key species, differed from patch to patch even within habitats. These differences were not correlated with position along the shore, and at this stage must be considered as unexplained variability.

In summary, removing eelgrass canopy had a weak but detectable effect on epifaunal assemblages and on the abundance and biomass of some taxa. The epifauna associated with habitat from which eelgrass was removed did not, however, match that from areas unvegetated prior to the experiment. This result suggests that the overriding importance of eelgrass to epifauna is not, at least over short periods, simply the presence of seagrass canopy. The evidence therefore supports models in which differences between the epifauna of vegetated and unvegetated habitats are not directly linked to the presence of seagrass canopy.

Acknowledgements. I thank Alan Butler, Craig Styan, Joanna Strzelecki and 2 referees for helpful comments, Graham Edgar for encouragement, and Andrew Melville and numerous other volunteers for assisting on the mudflats. This work was done while I was supported by an Australian Postgraduate Research Award. The PRIMER statistical package was kindly made available by Bob Clarke (Plymouth Marine Laboratory)

\section{LITERATURE CITED}

Bell, J. D., Pollard, D. A. (1989). Ecology of fish assemblages and fisheries associated with seagrasses. In: Larkum, A. W. D., McComb, A. J., Shepherd, S. A. (eds.) Biology of seagrasses. Elsevier, Amsterdam, p. 536-564

Bell, J. D., Westoby, M. (1986a). Importance of local changes in leaf height and density to fish and decapods associated 
with scugrass. J. cxp mar. Biol. Ecol. 104: 249-274

Bell, J. D., Westoby, M. (1986b). Abundance of macrofauna in dense seagrass is due to habitat preference, not predation. Oecologia 68: 205-209

Bell, S. S., Hicks, R. F. (1991). Marine landscapes and faunal recruitment: a field test with seagrasses and copepods. Mar. Ecol. Prog. Ser. 73: 61-68

Clarke, K. R. (1993). Non-parametric multivariate analyses of changes in community structure. Aust. J. Ecol. 18: $117-143$

Clarke, K. R., Warwick, R. M. (1994). Similarity-based testing for community pattern: the two-way layout with no replication. Mar. Biol. 118: 167-176

Clarke, K. R., Warwick, R. M., Brown, B. E. (1993). An index showing breakdown of seriation, related to disturbance, in a coral-reef assemblage. Mar. Ecol. Prog. Ser. 102: $153-160$

Connolly, R. M. (1994a). A comparison of fish assemblages from seagrass and unvegetated areas of a southern Australian estuary. Aust. J. mar. Freshwat. Res. 45(6); $1033-1044$

Connolly, R. M. (1994b). The role of shallow seagrass meadows as habitat for fish. Ph.D. dissertation, University of Adelaide

Connolly, R. M. (1994c). Removal of seagrass canopy: effects on small fish and their prey. J. exp. mar. Biol. Ecol. 184: $99-110$

Edgar, G. J. (1990a). The use of the size structure of benthic macrofaunal communities to estimate faunal biomass and secondary production. J. exp. mar. Biol. Ecol. 137: 195-214

Edgar, G. J. (1990b). The influence of plant structure on the species richness, biomass and secondary production of macrofaunal assemblages associated with Western Australian seagrass beds. J. exp. mar. Biol. Ecol. 137: 215-240

Gee, J. M. (1989). An ecological and economic review of meiofauna as food for fish. Zool. J. Linn. Soc. 96: 243-261

Heck, K. L., Orth, R. J. (1980). Seagrass habitats; the roles of habitat complexity, competition and predation in structuring associated fish and motile invertebrate assemblages. In: Kennedy, V. S. (ed.) Estuarine perspectives. Academic Press, New York, p. 449-464

Howard, R. K. (1987). Diel variation in the abundance of epifauna associated with seagrasses of the Indian River,

This article was submitted to the editor
Florida, USA. Mar. Biol. 96: 137-142

Howard, R. K., Edgar, G. J., Hutchings, P. A. (1989). Faunal assemblages of seagrass beds. In: Larkum, A. W. D., McComb, A. J., Shepherd, S. A. (eds.) Biology of seagrasses. Elsevier, Amsterdam, p. 536-564

Klumpp, D. W. Howard, R. K., Pollard, D. A. (1989). Trophodynamics and nutritional ecology of seagrass communities. In: Larkum, A. W. D., McComb, A. J., Shepherd, S. A. (eds.) Biology of seagrasses. Elsevier, Amsterdam, p $394-457$

Leber, K. M. (1985). The influence of predatory decapods, refuge, and microhabitat selection on seagrass communities. Ecology 66: 1951-1964

Lewis, F. C. (1984). Distribution of macrobenthic crustaceans associated with Thalassia, Halodule and bare sand substrata. Mar. Ecol. Prog. Ser. 19: 101-113

Orth, R. J., Heck, K. L., Van Montfrans, J. (1984). Faunal communities in seagrass beds: a review of the influence of plant structure and prey characteristics on predator-prey relationships. Estuaries 7: 339-350

Pollard, D. A. (1984). A review of ecological studies on seagrass-fish communities, with particular reference to recent studies in Australia. Aquat. Bot. 18: 3-42

Sergeev, V. N., Clarke, S. M., Shepherd, S. A. (1988). Motile macroepifauna of the seagrasses, Amphibolis and Posidonia, and unvegetated sandy substrata in Holdfast Bay, South Australia. Trans. R. Soc. S. Aust. 112: 97-108

Shepherd, S. A., McComb, A. J., Bulthuis, D. A., Neverauskas, V., Steffensen, D. A., West, R. (1989). Decline of seagrasses. In: Larkum, A. W. D., McComb, A. J., Shepherd, S. A. (eds.) Biology of seagrasses. Elsevier, Amsterdam, p. 346-393

Stoner, A. W. (1980). Perception and choice of substratum by epifaunal amphipods associated with seagrasses. Mar Ecol. Prog. Ser. 3: 105-111

Virnstein, R. W., Curran, M. C. (1986). Colonization of artificial seagrass versus time and distance from source. Mar. Ecol. Prog. Ser. 29: 279-288

Walker, D. I., McComb, A. J. (1992). Seagrass degradation in Australian coastal waters. Mar. Pollut. Bull. 25: 191-195

Warwick, R. M. (1988). Analysis of community attributes of the macrobenthos of Frierfjord/Langesundfjord at taxonomic levels higher than species. Mar. Ecol. Prog. Ser. 46 $167-170$

Manuscript first received: June 30, 1994

Revised version accepted: November 28, 1994 